\title{
Evidence for the Presence of Oxidatively Modified Low Density Lipoprotein in Atherosclerotic Lesions of Rabbit and Man
}

\author{
Seppo Ylä-Herttuala, Wulf Palinski, Michael E. Rosenfeld, Sampath Parthasarathy, \\ Thomas E. Carew, Susan Butler, Joseph L. Witztum, and Daniel Steinberg \\ Division of Endocrinology and Metabolism, Department of Medicine, University of California, \\ San Diego, La Jolla, California 92093-0613
}

\begin{abstract}
Three lines of evidence are presented that low density lipoproteins gently extracted from human and rabbit atherosclerotic lesions (lesion LDL) greatly resembles LDL that has been oxidatively modified in vitro. First, lesion LDL showed many of the physical and chemical properties of oxidized LDL, properties that differ from those of plasma LDL: higher electrophoretic mobility, a higher density, higher free cholesterol content, and a higher proportion of sphingomyelin and lysophosphatidylcholine in the phospholipid fraction. A number of lower molecular weight fragments of apo $B$ were found in lesion LDL, similar to in vitro oxidized LDL. Second, both the intact apo $B$ and some of the apo $B$ fragments of lesion LDL reacted in Western blots with antisera that recognize malondialdehyde-conjugated lysine and 4-hydroxynonenal lysine adducts, both of which are found in oxidized LDL; plasma LDL and LDL from normal human intima showed no such reactivity. Third, lesion LDL shared biological properties with oxidized LDL: compared with plasma LDL, lesion LDL produced much greater stimulation of cholesterol esterification and was degraded more rapidly by macrophages. Degradation of radiolabeled lesion LDL was competitively inhibited by unlabeled lesion LDL, by LDL oxidized with copper, by polyinosinic acid and by malondialdehyde-LDL, but not by native LDL, indicating uptake by the scavenger receptor(s). Finally, lesion LDL (but not normal intimal LDL or plasma LDL) was chemotactic for monocytes, as is oxidized LDL. These studies provide strong evidence that atherosclerotic lesions, both in man and in rabbit, contain oxidatively modified LDL.
\end{abstract}

\section{Introduction}

Plasma lipoproteins, particularly LDL, are the source of the lipid that accumulates in the atherosclerotic lesion $(1,2)$. Monocyte-derived macrophages, which are the precursors of most of the foam cells found in early atherosclerotic lesions (3-6), do not take up native LDL rapidly enough in vitro to become foam cells (7). However, several forms of chemically modified LDL are taken up more rapidly by way of a distinct receptor, the acetyl LDL receptor (7-9). Oxidatively modified

Address reprint requests to Dr. Joseph L. Witztum, Department of Medicine, M-013D, University of California, San Diego, La Jolla, CA 92093-0613.

Received for publication 14 February 1989 and in revised form 5 May 1989.

J. Clin. Invest.

(c) The American Society for Clinical Investigation, Inc.

$0021-9738 / 89 / 10 / 1086 / 10 \$ 2.00$

Volume 84, October 1989, 1086-1095
LDL is also recognized by the acetyl LDL receptor (10-14) and recent evidence strongly suggests that oxidative modification may play a significant role in atherogenesis in vivo (2, 15-18). This proposition is importantly supported by the recent demonstration that antioxidant therapy inhibits atherosclerosis in the Watanabe heritable hyperlipidemic (WHHL) ${ }^{1}$ rabbit $(15,16)$. Direct demonstration of oxidized LDL in atherosclerotic lesions would considerably strengthen the case for its pathogenetic role. Several groups have reported isolation from the aorta of lipoproteins with altered properties (19-26) but whether these represent oxidatively modified LDL or other modified forms of LDL remains uncertain.

It is unlikely that oxidative modification of LDL generates a single, reproducible form of modified LDL. More likely the oxidized LDL is a heterogeneous mixture of particles containing molecules that have been modified to different degrees and may even differ qualitatively. During the oxidative degradation of polyunsaturated fatty acids, a variety of reactive aldehyde products are formed and these are capable of attaching covalently to protein, particularly to the epsilon amino groups of lysine residues (2, 27-30). Malondialdehyde (MDA) and 4-hydroxynonenal (4-HNE) are two examples of such products but there are many others (28). Haberland et al. (17), using immunohistochemical techniques, reported evidence for the presence of MDA-LDL in the atherosclerotic lesions of WHHL rabbits. Palinski et al. (18) confirmed this finding and also presented immunohistochemical and immunological evidence for the presence of 4-HNE-conjugated LDL in rabbit aortic lesions. In the latter studies, it was also shown that LDL extracted from such lesions was recognized by antibodies against MDA-LDL.

The LDL molecule is notoriously unstable, readily undergoing oxidation, denaturation and aggregation (31-33). For example, Khoo et al. (33) have shown that vortexing a solution of $\mathrm{LDL}$ for as little as $30 \mathrm{~s}$ leads to extensive self-aggregation. Consequently, there is a real possibility that homogenization of the aorta may introduce artifacts. The methods introduced by Smith (1) and by Ylä-Herttuala et al. (24) are designed to avoid conditions that might lead to denaturation or aggregation. In the present studies, we have used the methods of YläHerttuala et al. (24) to determine (a) whether LDL gently extracted from the aorta has been altered in any way that might enhance its uptake by macrophages; and, specifically, (b) whether the lesions contain oxidatively modified LDL.

1. Abbreviations used in this paper: BHT, butylated hydroxytoluene; 4-HNE, 4-hydroxynonenal; HSA, human serum albumin; LPDS, lipoprotein-deficient sera; MDA, malondialdehyde; MPM, mouse peritoneal macrophages; poly I, polyinosinic acid; PPACK, D-phenylalanyl-L-prolyl-L-arginine chloromethyl ketone; TBARS, thiobarbituric acid-reactive substances; WHHL rabbit, Watanabe heritable hyperlipidemic rabbit. 


\section{Methods}

Materials. Carrier-free $\mathrm{Na}^{125}$ I-iodide was purchased from Amersham Corp. (Arlington, IL). $\left[{ }^{14} \mathrm{C}\right]$ Oleate was from Research Products International Corp. (Mount Prospect, IL). Ham's F-10 medium, DME, Iscove's medium and cell culture supplies, including PBS, were from Gibco Laboratories (Grand Island, NY). PBS used for other than cell culture experiments contained $140 \mathrm{mM} \mathrm{NaCl}, 3 \mathrm{mM} \mathrm{KCl}, 8 \mathrm{mM}$ $\mathrm{Na}_{2} \mathrm{HPO}_{4}, 2 \mathrm{mM} \mathrm{KH} \mathrm{PO}_{4}$, and $0.27 \mathrm{mM}$ EDTA (pH 7.4). Butylated hydroxytoluene (BHT) was from J. T. Baker Chemical Co. (Phillipsburg, NJ). Aprotinin, elastatinal, leupeptin, PMSF, polyinosinic acid (poly I), tetramethoxypropane, Coomassie brilliant blue and high molecular weight markers were from Sigma Chemical Co. (St. Louis, MO). D-Phenylalanyl-L-prolyl-L-arginine chloromethyl ketone (PPACK) and benzamidine were from Calbiochem-Behring Corp. (La Jolla, CA). Silver staining reagents were from National Diagnostics (Somerville, NJ). Probucol was a gift from the Merrell Dow Research Institute (Cincinnati, $\mathrm{OH}$ ) and was used as a concentrated ethanol solution.

Agarose electrophoresis gels were from Corning Medical Co. (Palo Alto, CA), and polyacrylamide gradient gels (4-12\%, Tefo-Gels) from Novex (Encinitas, CA). Tween 20, nitrocellulose membranes, and Enzymobeads were from Bio-Rad Laboratories (Richmond, CA). Affinity-purified goat anti-human IgG, anti-mouse IgG, anti-rabbit IgG, and anti-guinea pig IgG were from Cooper Biomedical (Malvern, PA). Iodogen was from Pierce Chemical Co. (Rockford, IL). X-Omat autoradiography film was purchased from Eastman Kodak Co. (Rochester, NY).

Collection of arterial specimens. Fresh human abdominal aortas and proximal iliac arteries were obtained from organ donors $(n=6$, mean age $40 \pm 12 \mathrm{yr}$ ) for renal transplants immediately after the surgery, washed with sterile saline, and placed in ice-cold lipoprotein extraction buffer containing antioxidants, protease inhibitors, and antibiotics (see below). Intima and inner media of grossly normal areas and areas containing fibro-fatty atherosclerotic lesions were isolated within $1 \mathrm{~h}$ after the removal of the arteries and buffer-soluble lipoproteins were extracted at $+4^{\circ} \mathrm{C}(24)$. A blood sample from the donor was drawn during surgery into the following preservatives (final concentrations): $2.7 \mathrm{mM}$ EDTA, $2 \mathrm{mM}$ benzamidine, $10 \mu \mathrm{M}$ probucol, $1 \mu \mathrm{M}$ PPACK, $0.01 \%$ aprotinin, $0.008 \%$ chloramphenicol, and $0.008 \%$ gentamycin. $1 \mathrm{mM}$ PMSF, $1 \mathrm{mM}$ leupeptin, and $40 \mu \mathrm{M}$ elastatinal were added to the plasma after the separation of blood cells. Plasma total cholesterol and triglyceride values of the patients were $181 \pm 61$ and $119 \pm 20 \mathrm{mg} / \mathrm{dl}$ (mean \pm SD), respectively.

2-3-yr-old WHHL rabbits were fasted overnight before study. Animals were anesthetized with intramuscular ketamine $(35 \mathrm{mg} / \mathrm{kg})$ and xylazine $(5 \mathrm{mg} / \mathrm{kg})$ and were exsanguinated by cannulating the right atrium through the jugular vein. Blood samples were taken for the isolation of plasma LDL in the presence of the preservatives listed above. To remove trapped blood from the aorta, the systemic circulation was perfused through the apex of the left ventricle with 2 liters of PBS containing $0.27 \mathrm{mM}$ EDTA and $10.0 \mu \mathrm{M}$ probucol. The whole aorta from arch to bifurcation was removed and cleaned of loose adventitial tissue. Samples were taken for immunocytochemistry (18) and intima-media was immediately dissected at $+4^{\circ} \mathrm{C}$. Areas containing grossly visible fibro-fatty atherosclerotic lesions were extracted for buffer-soluble lipoproteins. A total of 23 animals were studied. Plasma total cholesterol and triglyceride values were $489 \pm 84$ and $260 \pm 91$ $\mathrm{mg} / \mathrm{dl}$ (mean $\pm \mathrm{SD}$ ), respectively.

All procedures were approved by the Committee on Investigations Involving Human Subjects and the Committee on Investigations Involving Animal Subjects of the University of California, San Diego.

Extraction of intimal lipoproteins. Dissected samples were cut into small pieces with a McIlwain tissue chopper (The Micle Laboratory Engineering Co., UK). Minced tissue or whole plasma was extracted overnight at $+4^{\circ} \mathrm{C}$ under nitrogen using an orbital shaker $(10 \mathrm{rpm})$ in $0.14 \mathrm{M} \mathrm{NaCl} / 0.01 \mathrm{M}$ phosphate buffer, $\mathrm{pH} 7.2$ (24), which contained the following preservatives (final concentrations): $2.7 \mathrm{mM}$ EDTA, 2
$\mathrm{mM}$ benzamidine, $1 \mathrm{mM}$ PMSF, $1 \mathrm{mM}$ leupeptin, $40 \mu \mathrm{M}$ elastatinal, $10 \mu \mathrm{M}$ probucol, $1 \mu \mathrm{M}$ PPACK, $0.01 \%$ aprotinin, $0.008 \%$ chloramphenicol, and $0.008 \%$ gentamycin. Plasma samples from the donors and WHHL rabbits were similarly handled, i.e., incubated in the presence of the same preservatives, antioxidants, and antibiotics. A total of $5 \mathrm{ml}$ extraction buffer (24) was used per gram wet tissue or per $5 \mathrm{ml}$ of plasma. The extract was collected by low-speed centrifugation at $+4^{\circ} \mathrm{C}$ and the supernatants were combined. The extract was transferred into $12-\mathrm{ml}$ tubes and overlayered with $0.5 \mathrm{ml}$ of water. The tubes were centrifuged at $100,000 \mathrm{~g}$ for $30 \mathrm{~min}$ at $+5^{\circ} \mathrm{C}$. A pellet at the bottom and a creamy layer at the top were discarded. The extract was then concentrated by low-speed centrifugation using Centricon filters (Amicon Corp., Danvers, MA) and subjected to density gradient ultracentrifugation (24).

Density gradient ultracentrifugation. The density of the extract was adjusted to $1.18 \mathrm{~g} / \mathrm{ml}$ by addition of solid $\mathrm{NaBr}$. A $6.50-\mathrm{ml}$ sample was placed in a tube and overlayered with $5.40 \mathrm{ml}$ of the lipoprotein extraction buffer $(d=1.004)$. The tubes were centrifuged at $150,000 \mathrm{~g}$ for $40 \mathrm{~h}$ at $+5^{\circ} \mathrm{C}$ in a model $\mathrm{L} 2$ ultracentrifuge using a SW41 rotor (Beckman Instruments, Fullerton, CA). A tube containing plasma from the tissue donor or WHHL rabbits and a background salt tube were included in each run. The density profile of the gradient was measured with a densitometer (Mettler-Paar model DMA 45; Anton Paar K.G., Graz, Austria). Lipoproteins were located by their light scattering under indirect illumination and collected by pipetting. LDL fractions were recentrifuged twice at $150,000 \mathrm{~g}$ for $24 \mathrm{~h}$ at $5^{\circ} \mathrm{C}$ at the density of $1.090 \mathrm{~g} / \mathrm{ml}$ in the presence of $0.27 \mathrm{mM}$ EDTA, $2 \mathrm{mM}$ benzamidine, 1 mM PMSF, $10 \mu \mathrm{M}$ probucol, $1 \mu \mathrm{M}$ PPACK, and antibiotics. In addition to the patient and WHHL rabbit lipoproteins, normal human LDL, and lipoprotein-deficient serum (LPDS) were isolated from healthy volunteers by preparative ultracentrifugation (34) in the presence of the same antioxidants, protease inhibitors, and antibiotics. Isolated lipoproteins were dialyzed against $0.14 \mathrm{M} \mathrm{NaCl} / 0.01 \mathrm{M}$ phosphate buffer (pH 7.4) containing $0.27 \mathrm{mM}$ EDTA, $1 \mathrm{mM}$ PMSF, 10 $\mu \mathrm{M}$ probucol, and antibiotics, sterile filtered $(0.45 \mu \mathrm{m})$, and stored under nitrogen at $+4^{\circ} \mathrm{C}$. If the lipoproteins were used for cell culture experiments, PMSF was omitted from the last changes of the dialyzing buffer. The mass of lesion LDL recovered varied between 0.04 and $0.17 \mathrm{mg}$ lipoprotein protein per gram of aorta.

Characterization of the isolated lipoproteins. Protein content of the lipoproteins was determined according to Lowry et al. (35) using BSA as a standard. In a separate experiment we tested the ability of the protein assay to measure oxidized LDL protein. Compared with an equal amount of control LDL, LDL oxidized with copper for $20 \mathrm{~h}$ gives $\sim 10 \%$ lower values in the Lowry assay (data not shown). The difference was considered small enough to justify the use of the Lowry assay in the present studies and results were not corrected. Total cholesterol and free and esterified cholesterol were analyzed using a nonenzymatic method (36). Triglycerides were determined using enzymatic methods (Boehringer-Mannheim Biochemicals, Indianapolis, IN). Total phospholipids and phospholipid subfractions were analyzed as described (12). Agarose electrophoresis (12), apo B distribution across the density gradient (37), and the assay for thiobarbituric acidreactive substances (TBARS) in the lipoproteins (12) were performed as described.

SDS-PAGE and immunoblotting. SDS-PAGE was done using 4-12\% gels in $0.025 \mathrm{M}$ Tris $0.19 \mathrm{M}$ glycine buffer, $\mathrm{pH} 8.3$, containing $0.1 \%$ SDS ( $100 \mathrm{~V}, 30 \mathrm{~mA}$ for $75 \mathrm{~min}$; Novex Mini Cell electrophoresis unit, Encinitas, CA). Before the electrophoresis, the samples were heated for $3 \mathrm{~min}$ in a boiling water bath. The sample buffer contained $0.063 \mathrm{M}$ Tris- $\mathrm{HCl}, 2 \%$ SDS, $10 \%$ glycerol, $10 \mu \mathrm{M}$ BHT, and $0.001 \%$ bromphenol blue ( $\mathrm{pH}$ 6.8). Because preliminary experiments showed that the ability of some antibodies (MB-19 [38], MAL-2, 4-HNE) to react with apolipoproteins was significantly reduced by prior reduction of the samples with 2-mercaptoethanol, the reducing agent was not included in the sample buffer. No difference was found in the electrophoretic mobility of apo B and its fragments in reduced and nonreduced samples. Coomassie brilliant blue and silver stainings were used to visualize protein bands. 
Transfer to nitrocellulose membranes for immunoblotting was done in the same electrophoresis unit at $+4^{\circ} \mathrm{C}$ for $80 \min (25 \mathrm{~V}, 160$ $\mathrm{mA}$ ). Transfer buffer contained $0.025 \mathrm{M}$ Tris/0.19 M glycine, $10 \mu \mathrm{M}$ BHT, and $15 \%$ methanol (vol/vol). After the transfer, nonspecific binding sites on the membranes were blocked by incubation at $+4^{\circ} \mathrm{C}$ for $6 \mathrm{~h}$ in PBS containing 3\% BSA or 5\% nonfat dried milk proteins (38). The membranes were then incubated for $12 \mathrm{~h}$ with primary antibodies in PBS containing $0.05 \%$ Tween 20 and $1 \%$ BSA or $1 \%$ nonfat dried milk proteins (38). The membranes were washed three times ( 30 min each) with the same buffer without antibodies and incubated for $4 \mathrm{~h}$ in the presence of ${ }^{125}$ I-labeled secondary antibodies. The membranes were then washed six times over $12 \mathrm{~h}$ in the same buffer without antibodies, dried, and subjected to autoradiography.

Antibodies. Six previously characterized MAbs specific for apo-B were used: MB-47 and MB-43, specific for apo $B$ thrombin fragment $T_{2} ; M B-44$, specific for $T_{3}$; MB-24, MB-19, and MB-3, specific for fragment $T_{1}(38-40)$. In addition, polyclonal antisera against human LDL (39), MDA-LDL (18), and reduced 4-HNE-LDL (18) were used. The antiserum against MDA-LDL (MAL-2) is specific for MDA-lysine adducts and recognizes this epitope on a variety of different proteins (18). Similarly, the antiserum against 4-HNE-LDL (4-HNE) is specific for the 4-HNE-lysine adduct (18). A full characterization of these antisera will be reported elsewhere. ${ }^{2}$ A MAb specific for human albumin (41) was also used. ${ }^{125}$ I-labeled affinity-purified goat IgG specific for human IgG, mouse IgG, rabbit IgG, or guinea pig IgG were used as secondary antibodies on Western blots. Antibodies were labeled using the lactoperoxidase method (Enzymobeads) according to the manufacturer's instructions. Typically, $1,000,000 \mathrm{cpm} / 10 \mu \mathrm{l}$ of the antibody solution was used per $10 \mathrm{ml}$ of the Western blot incubation buffer.

Lipoprotein modification and radioiodination. Copper-oxidized LDL was made by incubating LDL $(100 \mu \mathrm{g} / \mathrm{ml})$ at $+37^{\circ} \mathrm{C}$ in Ham's $\mathrm{F}-10$ for $3 \mathrm{~h}$ or $18 \mathrm{~h}$ in the presence of $10 \mu \mathrm{M}$ cupric sulfate (42). MDA-LDL was prepared at $+4^{\circ} \mathrm{C}$ by repeated additions of freshly prepared MDA. MDA was liberated by incubating $0.1 \mathrm{ml}$ tetramethoxypropane with $0.5 \mathrm{ml} 4 \mathrm{~N} \mathrm{HCl}$ at $+60^{\circ} \mathrm{C}$ for $30 \mathrm{~min}$. The solution was neutralized with $4 \mathrm{~N} \mathrm{NaOH}$ and brought to $2.7 \mathrm{ml}$ with distilled water. $10 \mu$ l of this solution was added to LDL ( $2 \mathrm{mg}$ in $0.8 \mathrm{ml}$ PBS containing no EDTA) in 5-min intervals during $3 \mathrm{~h}$. After the additions, LDL was extensively dialyzed against PBS. Acetylated LDL (43) and reduced 4-HNE-LDL ${ }^{2}$ (27) were made as described. The extent of LDL modification was checked by agarose electrophoresis.

Lipoproteins were labeled with carrier-free sodium ${ }^{125} \mathrm{I}$-iodide using the Iodogen method (44). To ensure equal conditions of iodination, lesion LDL and control plasma LDL were always iodinated simultaneously at the same protein concentration. Specific activities varied from 50 to $450 \mathrm{cpm} / \mathrm{ng}$ lipoprotein protein. The percentage of ${ }^{125}$ I radioactivity precipitated by TCA was $>96 \%$.

Cell culture studies. Resident mouse peritoneal macrophages (MPM) were isolated from Swiss Webster mice as described (14). Before the experiments, the cells were incubated for $24 \mathrm{~h}$ in DME containing $3.3 \mathrm{mg} / \mathrm{ml}$ LPDS. Human monocyte-macrophages were isolated (45) and cultured in Iscove's medium supplemented with $30 \%$ human serum, $8 \mu \mathrm{g} / \mathrm{ml}$ insulin, and $2 \mathrm{mg} / \mathrm{ml}$ glucose for $6-8 \mathrm{~d}$. Before the incubations, the cells were incubated for $24 \mathrm{~h}$ in Iscove's medium containing $5 \mathrm{mg} / \mathrm{ml}$ LPDS.

Macrophage degradation of ${ }^{125}$ I-labeled lipoproteins was carried out by incubating the cells for $6 \mathrm{~h}$ in DME medium containing 3.3 $\mathrm{mg} / \mathrm{ml}$ of LPDS and 2 or $5 \mu \mathrm{g} / \mathrm{ml}$ of the labeled lipoproteins, followed by the determination of the noniodide TCA-soluble radioactivity (46). The incorporation of $\left[{ }^{14} \mathrm{C}\right]$ oleate into cellular cholesteryl esters was studied by incubating the cells in the presence of $0.2 \mathrm{mM}\left[{ }^{14} \mathrm{C}\right]$ oleate/ albumin, 3.3 or $5 \mathrm{mg} / \mathrm{ml} \mathrm{LPDS}$, and $25 \mu \mathrm{g} / \mathrm{ml}$ of the lipoproteins (47). Cellular lipids were extracted in situ using hexane-isopropanol (3:2; vol/vol). Labeled cholesteryl esters were isolated using TLC and

2. Palinski, W., S. Ylä-Herttuala, M. E. Rosenfeld, S. W. Butler, S. A. Socher, S. Parthasarathy, L. K. Curtiss, and J. L. Witztum, manuscript in preparation. counted for $\left[{ }^{14} \mathrm{C}\right]$ radioactivity. All lipoproteins were sterile filtered $(0.45 \mu \mathrm{m})$ immediately before the cell culture experiments.

Chemotaxis assay. Chemotaxis was measured in a modified Boyden chamber using freshly prepared human monocytes as described (48).

\section{Results}

Extraction of aortic $L D L$. In this study, fresh human and WHHL rabbit arteries were subjected to the gentlest possible extraction in the presence of antioxidants, antibiotics, and protease inhibitors. We believe this is critically important if one is to understand the nature of the lipoproteins as they exist in the intima. Homogenization or other vigorous extraction procedures can readily lead to denaturation, aggregation, and even to the generation of artifactual lipid-protein complexes. The latter may have some of the properties of lipoproteins but they may be actually created during the process of isolation. In all of the studies reported here, a sample of plasma LDL was taken from the organ donor or from the animal donor and subjected to exactly the same procedures used in the handling of the tissue LDL. We found no evidence for oxidation of the control plasma LDL studied in this way. Furthermore, when plasma LDL $(0.25 \mathrm{mg})$ was added to minced normal or atherosclerotic intimal tissue $(1 \mathrm{~g})$ and then reisolated by the standard procedure, there was no evidence of oxidative modification as shown by SDS-PAGE, Western blotting with MB-47 and MAL-2, and by cell culture studies (data not shown).

To estimate the recoveries of LDL from the artery, trace amounts of ${ }^{125} \mathrm{I}$-labeled WHHL rabbit plasma LDL $\left(10^{7} \mathrm{cpm}\right.$ total radioactivity per animal) were injected into five WHHL rabbits $2 \mathrm{~h}$ before killing. At killing, $1 \mathrm{~g}$ of lesion contained $\sim 0.0003 \%$ of the total injected radioactivity. Of the ${ }^{125} \mathrm{I}-\mathrm{LDL}$ in the artery wall at that time, $50-60 \%$ could be recovered using our standard extraction procedure. When the extraction was repeated using a buffer of higher ionic strength $(1.5 \mathrm{M}$ $\mathrm{NaCl}$ ), only an additional $10-15 \%$ of the total ${ }^{125}$ I-LDL was extracted. Whether or not the residual lipoprotein that cannot be removed by gentle extraction represents modified or unmodified LDL cannot be determined. Similarly, it is unclear what percent of LDL chronically present in the artery wall is extracted by our procedure. Nevertheless, because of the risk of producing artifacts, we did not use more vigorous extraction procedures but studied only that LDL that was readily removed into the buffer using the standard gentle procedure. In addition, to avoid using any lesion LDL that may have been aggregated, all samples were sterile filtered before the studies described below.

Physical and chemical properties of lesion $L D L$. On density gradient ultracentrifugation, lesion LDL appeared to be a single peak. The distribution of total cholesterol and of immunologically detectable apo $\mathrm{B}$ across the density gradient were nearly identical (Fig. $1 A$ ). The density of lesion LDL was higher than that of the corresponding control plasma LDL (Fig. $1 B$, Table I), but the density of the LDL isolated from normal human intima was not increased (Table I). The relative electrophoretic mobility of human and WHHL rabbit lesion LDL was increased (Table I). LDL isolated from normal human intima also had an increased electrophoretic mobility relative to plasma LDL (Table I).

The total cholesterol to protein ratio of both human and WHHL rabbit lesion LDL was increased compared with that 
A

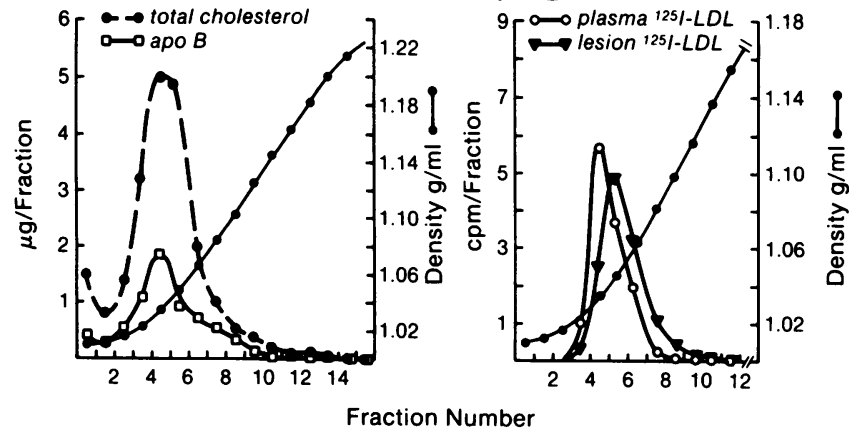

Figure 1. Density profile of LDL isolated from plasma and from atherosclerotic lesions of WHHL rabbits. The density of the samples was brought to $1.18 \mathrm{~g} / \mathrm{ml}$ by the addition of solid $\mathrm{NaBr}$. A $6.50-\mathrm{ml}$ sample of the $d=1.18 \mathrm{~g} / \mathrm{ml}$ solution containing the lipoproteins was overlayered with $5.40 \mathrm{ml}$ of $d=1.004 \mathrm{~g} / \mathrm{ml}$ solution and centrifuged at $150,000 \mathrm{~g}$ for $40 \mathrm{~h}$ at $+5^{\circ} \mathrm{C}$ as described in Methods. Fractions were collected from the top of the tubes and their densities measured with a Mettler-Paar densitometer. $(A)$ Distributions of total cholesterol and immunoreactive apo $B$ across the gradient containing the crude extract of WHHL rabbit lesion LDL. $(B)$ Density distribution of ${ }^{125}$ I-labeled WHHL rabbit plasma LDL and lesion LDL. Both lipoproteins were isolated as described in Methods, radioiodinated and aliquots of the labeled lipoproteins were mixed with unlabeled carrier lipoproteins. All samples were pooled from eight animals.

in their respective plasma LDL. Of the total cholesterol in WHHL rabbit lesion LDL, $66 \%$ was in free form, whereas in WHHL rabbit plasma LDL only $24 \%$ of the total cholesterol was free (Table I). Because of the relatively small amount of LDL extractable from even atherosclerotic arterial tissue, composition analysis was done only on one preparation of WHHL rabbit lesion LDL (combined from eight animals). The percentage composition of lesion LDL was as follows: free cholesterol, 29.0\%; cholesteryl esters, $27.5 \%$; phospholipids, $21.8 \%$; triglycerides, $6.4 \%$; and total protein, $15.3 \%$. Corresponding values for WHHL rabbit plasma LDL were: 11.5 , $42.9,22.9,5.6$, and $17.1 \%$, respectively. Phospholipid subfractions in the same lesion LDL were (percentage of total phospholipids): lysophosphatidylcholine, $10.4 \%$; phosphatidylcholine, 25.4\%; and sphingomyelin, $61.3 \%$; with corresponding WHHL rabbit plasma LDL values of 3.4, 67.8, and $25.0 \%$, respectively.

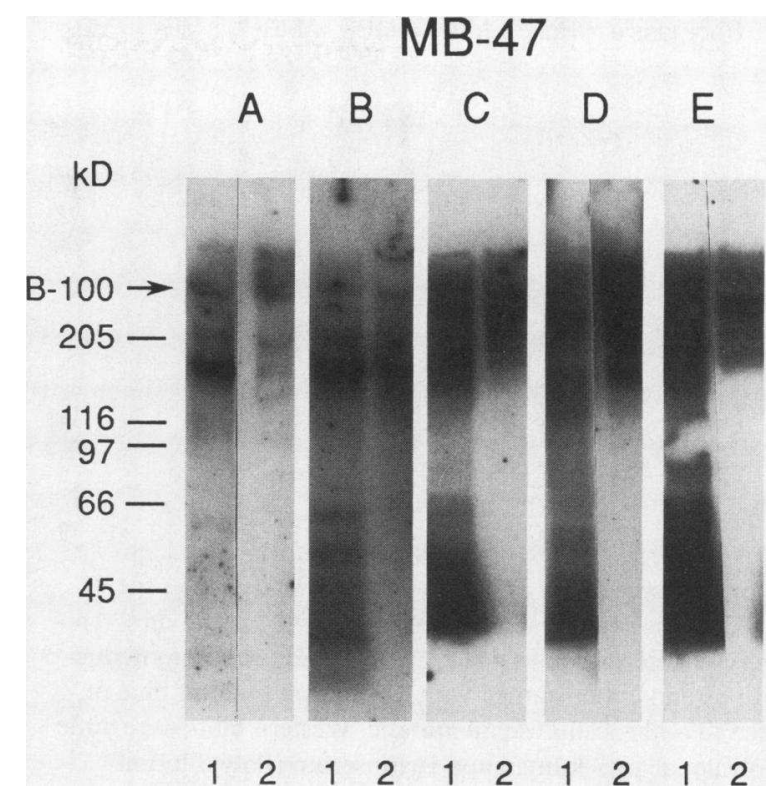

Figure 2. Western blots of lesion LDL (lane 1 ) and the corresponding plasma LDL (lane 2) from five male human subjects, aged 38, $25,28,41$ and 51 yr old (lanes $A-E$, respectively). LDL was isolated as described in Methods. Apolipoproteins were separated in 4-12\% SDS-PAGE under nonreducing conditions and transblotted to a nitrocellulose membrane. Western blots were done using the apo Bspecific MAb MB-47 (dilution 1:1,000). Each lane contains $10 \mu \mathrm{g}$ protein.

No increased amounts of TBARS could be found in lesion LDL. This observation is not unexpected because of the known loss of the polar TBARS that occurs during the ultracentrifugation and dialysis involved in purification of lesion $\operatorname{LDL}(28,29)$.

Immunologic studies of lesion $L D L$. In all lesion LDL samples studied, Western blot analyses with the apo B-specific MAb MB-47 showed an extensive degradation of lesion LDL apo B (Fig. 2). Less apparent breakdown of apo B was evident with five other apo B-specific MAbs (Fig. 3), presumably because these antibodies did not detect some of the fragments that MB-47 did. Some breakdown products were even found in control plasma LDL, which is probably due to the high sensitivity of the Western blotting method. It is noteworthy

Table I. Characterization of LDL Isolated from Plasma and Aortic Intima

\begin{tabular}{|c|c|c|c|c|c|}
\hline & $n$ & Density range* & $\begin{array}{l}\text { Total cholesterol/ } \\
\text { total protein }\end{array}$ & $\begin{array}{l}\text { Free cholesterol/ } \\
\text { total cholesterol }\end{array}$ & Electrophoretic mobility ${ }^{\ddagger}$ \\
\hline \multicolumn{6}{|c|}{$g / m l$} \\
\hline \multicolumn{6}{|l|}{ Human } \\
\hline Plasma LDL & 6 & $1.035-1.047$ & $1.43 \pm 0.18$ & ND & 1.0 \\
\hline Normal intimal LDL & 2 & $1.030-1.045$ & $1.44 \pm 0.10$ & & $1.8 \pm 0.10$ \\
\hline Lesion LDL & 6 & $1.040-1.070$ & $2.38 \pm 0.33$ & & $2.0 \pm 0.24$ \\
\hline \multicolumn{6}{|l|}{ WHHL rabbit ${ }^{\S}$} \\
\hline Plasma LDL & 3 & $1.031-1.048$ & $1.28 \pm 0.17$ & $0.24 \pm 0.03$ & 1.0 \\
\hline Lesion LDL & 3 & $1.043-1.072$ & $2.50 \pm 0.29$ & $0.65 \pm 0.08$ & $1.6 \pm 0.08$ \\
\hline
\end{tabular}

Values are mean \pm SD. ${ }^{*}$ Mean density range of the isolated lipoproteins. ${ }^{\ddagger} R(f)$ relative to plasma $L D L$ on agarose electrophoresis $(0.05 \mathrm{M}$ barbital buffer, pH 8.6). \$ Three pools of animals containing five, eight, and eight animals, respectively. 


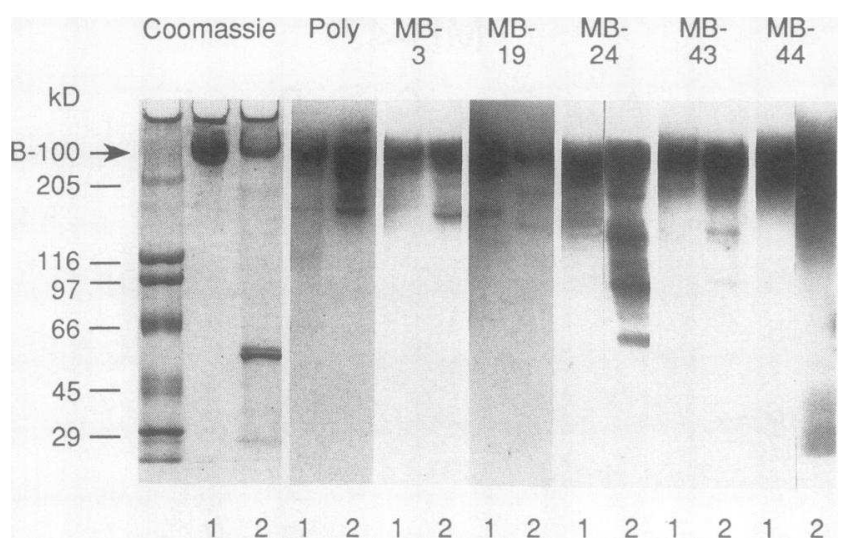

Figure 3. Immunoreactivity of a human lesion LDL (male, age 41 yr, subject D in Fig. 2) with different apo B-specific antibodies. Apolipoproteins were separated in 4-12\% SDS-PAGE under nonreducing conditions and either stained with Coomassie brilliant blue or transblotted to a nitrocellulose membrane. Western blots were done using a polyclonal anti-human apo B antiserum (Poly dilution 1:200) or with monoclonal antibodies MB-3, MB-19, MB-24, MB-43, and MB-44 (each at dilution 1:1,000). Lane 1, Plasma LDL; lane 2 , Lesion LDL. Each lane contains $10 \mu \mathrm{g}$ protein. The lane at left contains molecular weight markers.

that neither Coomassie blue nor silver staining detected the full extent of degradation of lesion LDL (Figs. 3 and 4), as previously shown (42). When LDL was isolated from both grossly normal intima and from atherosclerotic lesions of the same subject and Western blotted with MB-47, normal intimal LDL tended to show fewer degradation products than lesion LDL (Fig. 4).

Apo B and lower molecular weight fragments in lesion LDL reacted with antibodies raised against MDA-LDL (MAL-2) and reduced 4-HNE-LDL (4-HNE) (Fig. 4). These antisera react with MDA-lysine adducts and 4-HNE-lysine adducts, respectively. The bands staining with MAL-2 coincided with bands also staining with the apo B-specific MAb MB-47.
The antiserum to 4-HNE-LDL also reacted with the same bands. In general, no such reactions were found with the patient's plasma LDL or with LDL isolated from normal human aortic intima (Fig. 4). In occasional plasma LDL samples, there was weak staining of apo B-100 by the antiserum to 4-HNE (Fig. 4) as well as by MAL-2. In the plasma LDL we never observed apo B fragments that were stained with MAL-2 or 4-HNE antisera. Small amounts of albumin and immunoglobulins (see below) were also detected in the isolated lesion LDL, but no albumin was present in the major MDA-positive bands (Fig. 4). Some of the MAL-2 positive bands in lesion LDL also coincided with the bands recognized by the apo $B$ specific MAbs, MB-19 (Fig. 5), MB-3 and MB-43 (data not shown).

Essentially similar results were obtained with lesion LDL isolated from WHHL rabbit atherosclerotic aortas. As shown in Fig. 6, considerable material reactive with MB-47 remained in the atherosclerotic tissue sample after the standard extraction of soluble lesion LDL. MAL-2-reactive material was recovered with the isolated lesion LDL, whereas most of the 4-HNE-reactive material was detected in the crude saline extract. However, with both antisera little, if any, reactivity was found in the $2.0 \%$ SDS buffer extract of the atherosclerotic tissue after the saline extraction of lesion LDL. Lesion LDL also contained immunologically detectable amounts of IgG (Fig. 6).

Biologic properties of lesion $L D L$. This laboratory has previously shown that oxidized LDL, but not native LDL, is chemotactic for human monocytes (48). LDL isolated from both human and WHHL rabbit lesions was also chemotactic for human monocytes, whereas plasma LDL and LDL isolated from normal human intima were not (Table II).

Human lesion LDL stimulated the incorporation of $\left[{ }^{14} \mathrm{C}\right]-$ oleate into cellular cholesteryl esters of human monocyte-macrophages sixfold relative to an LPDS control (Table III); the stimulation by human plasma LDL was only twofold. LDL isolated from the lesions of WHHL rabbits increased cholesterol esterification in MPM fourfold (Table IV) whereas WHHL plasma LDL had almost no effect. Compared with
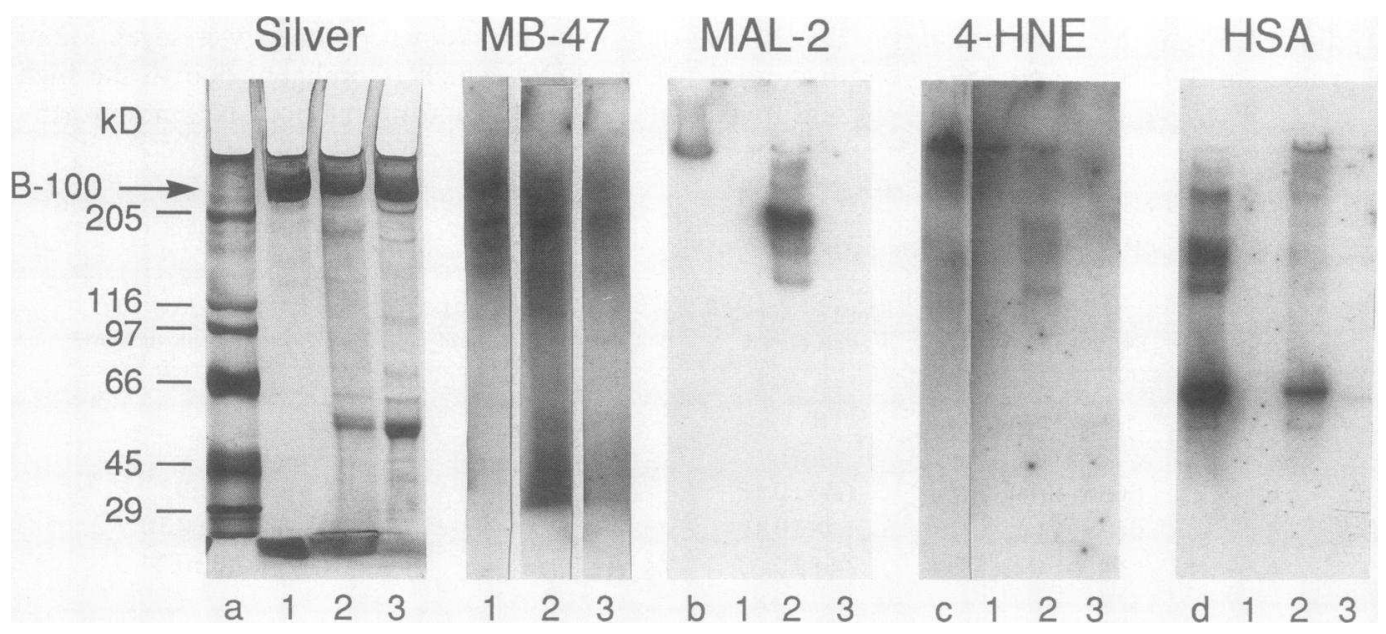

Figure 4. SDS-PAGE and Western blot analysis of LDL isolated from plasma and from normal and atherosclerotic human aorta of a 54-yr-old male. Apolipoproteins were separated in 4-12\% SDSPAGE under nonreducing conditions and either silver-stained or transblotted to a nitrocellulose membrane. Western blots were done using the apo Bspecific MAb MB-47 (dilution 1:1,000), polyclonal antisera MAL-2

(dilution 1:200) and 4-HNE (dilution 1:100), and an anti-human albumin MAb (HSA) (dilution 1:500). Lane 1, Plasma LDL; lane 2, lesion LDL; lane 3, LDL isolated from grossly normal aortic intima; lane $a$, high molecular weight markers; lane $b$, MDA-modified human LDL standard; lane $c$, 4-HNE-modified human LDL standard; lane $d$, HSA. An arrow indicates the position of B-100. Staining above the level of B-100 in lanes $b$ and $c$ presumably indicates the presence of aggregated LDL. Each lane contains $10 \mu \mathrm{g}$ protein except the lanes in silver-stained gel, and lanes $a, b, c$, and $d$, which contain $5 \mu \mathrm{g}$ protein. 


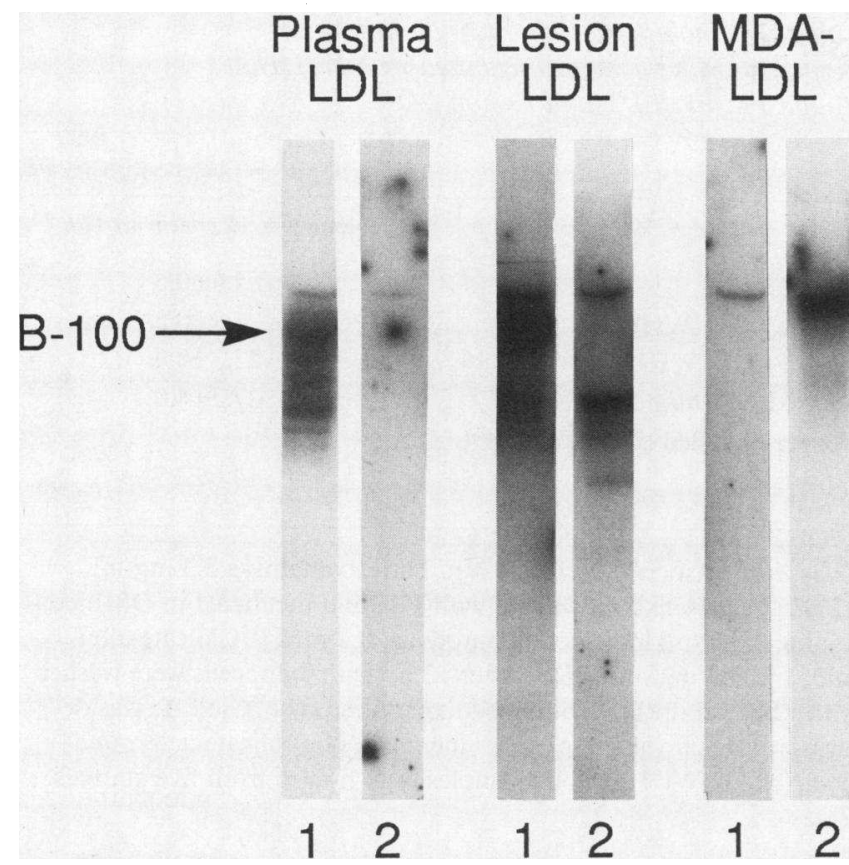

Figure 5. Western blot analysis of LDL isolated from atherosclerotic human aorta of a 38-yr-old male (subject A, Fig. 2). Apolipoproteins were separated in 4-12\% SDS-PAGE under nonreducing conditions and transblotted to a nitrocellulose membrane. Plasma LDL, LDL isolated from the patient's plasma. Lesion LDL, LDL isolated from atherosclerotic lesions; MDA-LDL, MDA-modified human LDL standard. Lane 1 was incubated with the apo B-specific MAb MB-19 (dilution 1:1,000); lane 2 was incubated with polyclonal antiserum MAL-2 (dilution 1:200). Arrow, the position of B-100. Staining above the level of B-100 presumably indicates the presence of aggregated LDL. Plasma LDL and lesion LDL contain $10 \mu \mathrm{g}$ protein/lane, MDA-LDL contains $5 \mu \mathrm{g}$ protein/lane. plasma LDL, human lesion LDL also stimulated oleate incorporation into cholesteryl esters of MPM fivefold (data not shown).

The degradation of ${ }^{125}$ I-labeled WHHL rabbit lesion LDL in MPM was increased eightfold compared with that of WHHL plasma LDL (Table V). As shown in Fig. 7, the degradation of WHHL rabbit lesion ${ }^{125}$ I-LDL was competed by unlabeled lesion LDL, poly I, MDA-LDL, and LDL oxidized with copper for $18 \mathrm{~h}$. Acetyl-LDL and LDL oxidized with copper for only $3 \mathrm{~h}$ were less effective, whereas WHHL rabbit plasma LDL did not compete.

Previous studies have shown that oxidized LDL is recognized and degraded poorly by the native LDL receptor of fibroblasts $(12,29)$. At the concentration of $20 \mu \mathrm{g}$ lipoprotein protein/ml incubation media, WHHL rabbit ${ }^{125}$ I-labeled lesion LDL was only marginally degraded by human fibroblasts $(0.1 \mu \mathrm{g} / \mathrm{mg}$ cell protein $/ 6 \mathrm{~h})$, whereas WHHL rabbit plasma LDL was readily degraded $(4.1 \mu \mathrm{g} / \mathrm{mg}$ cell protein $/ 6 \mathrm{~h})$.

\section{Discussion}

These studies present three lines of evidence for the presence of oxidatively modified LDL in human and in rabbit atherosclerotic lesions. First, lesion LDL greatly resembles oxidized LDL in its physical and chemical properties. Lesion LDL as isolated showed a reasonably sharp density profile (Fig. 1) with a modal density slightly greater than that of plasma LDL, as is the case for oxidized LDL (11). In agreement with previous findings, lesion LDL had increased electrophoretic mobility (19, 21-26), contained more free cholesterol $(23,25,26)$ and had a higher percentage of lysophosphatidylcholine in the total phospholipids (26) compared with control plasma LDL. In addi-
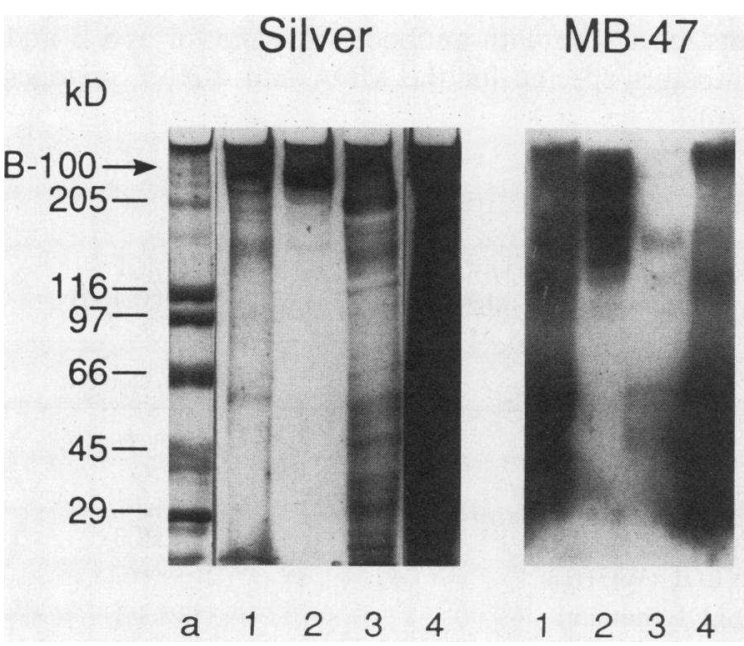
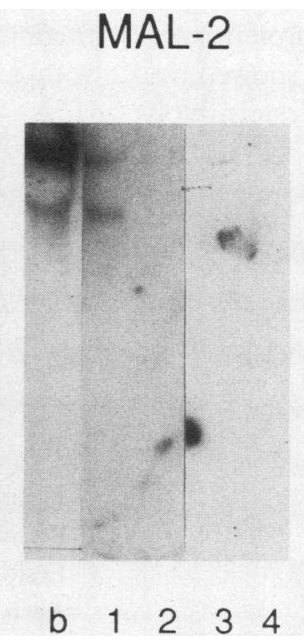

\section{4-HNE}

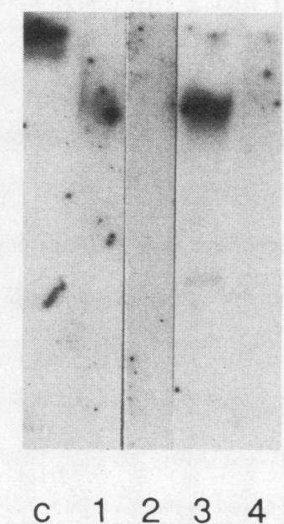

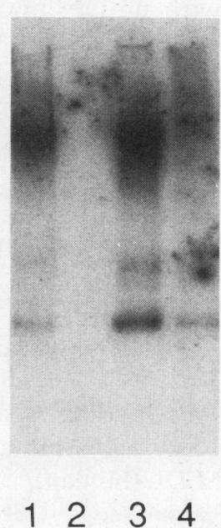

Figure 6. SDS-PAGE and Western blot analysis of plasma LDL and lesion LDL isolated from atherosclerotic WHHL rabbit aortas. Apolipoproteins were separated in 4-12\% SDS-PAGE under nonreducing conditions and either silver-stained or transblotted to a nitrocellulose membrane. Western blots were done using the apo B-specific MAb MB-47 (dilution 1:1,000), polyclonal antisera MAL-2 (dilution 1:200) and 4-HNE (dilution 1:200), and affinity-purified goat anti-rabbit IgG (dilution 1:800). WHHL rabbit samples were pooled from eight animals. Lane 1, lesion LDL; lane 2, WHHL rabbit plasma LDL; lane 3, crude saline extract of the atherosclerotic aortas before isolation of lesion LDL; lane 4, Tissue from the atherosclerotic aortas after the extraction of buffer-soluble LDL. $40 \mathrm{mg}$ of dry delipidated aortic tissue was incubated in $400 \mu \mathrm{l}$ of SDS-PAGE sample buffer at $+20^{\circ} \mathrm{C}$ for $20 \mathrm{~h}$, and an aliquot of the extract was analyzed. Lane $a$, molecular weight markers; lane $b$, MDA-modified human LDL standard; lane $c$, 4-HNE-modified human LDL standard. An arrow indicates the position of B-100. Staining above the level of B-100 in lanes $b$ and $c$ presumably indicates the presence of aggregated LDL. Protein content in the silver-stained gel: $5 \mu \mathrm{g}$ per lane, except lane 4, which contains $35 \mu \mathrm{g}$. Protein content in the Western blots: lanes 1-3, $10 \mu \mathrm{g}$; lane 4, $35 \mu \mathrm{g}$; lanes $b$ and $c, 5 \mu \mathrm{g}$. 
Table II. Chemotactic Activity for Human Monocytes of LDL Isolated from Plasma and from Normal and Atherosclerotic Aortic Intima

\begin{tabular}{lc}
\hline & Chemotactic index* $^{*}$ \\
\hline Human $^{\ddagger}$ & \\
Plasma LDL & 1.15 \\
Normal intimal LDL & 1.50 \\
Lesion LDL & 6.60 \\
WHHL rabbit & \\
Plasma LDL & 0.82 \\
Lesion LDL & 8.25
\end{tabular}

* Number of cells migrating in response to the test substance divided by the number of cells migrating when control medium is present in both chambers. Each value is the average of duplicate determinations. In the control experiment, $51 \pm 11$ cells per high power field migrated to the membrane.

${ }^{\ddagger}$ Human sample, 54-yr-old male; WHHL rabbit samples were pooled from eight animals.

tion, there was extensive fragmentation of apo B, typical of oxidatively modified LDL (42).

A second line of evidence comes from the use of immunologic techniques. The antisera used here were specific for epitopes present in oxidized LDL but absent from native LDL. They were generated using models of oxidized LDL, i.e., MDA-conjugated LDL and 4-HNE-conjugated LDL. These are among the several modifications of apo B generated by aldehyde fragments, formed during oxidation of polyunsaturated fatty acids, which complex with epsiolon-amino groups of lysine residues $(2,27-29)$. The model modified forms of LDL were injected into homologous species so that antibodies against the native LDL were not generated. Thus the antisera produced were adduct specific, i.e., MAL-2 recognizes MDAlysine residues (present on any protein) and antiserum 4-HNE recognizes 4-HNE-lysine residues (present on any protein). As expected, Western blot analysis with these antisera showed no reaction with native, plasma LDL. In contrast, Western blot

Table III. Cholesterol Esterification in Human Monocyte-Macrophages Incubated with Human Plasma $L D L$ and Lesion $L D L$

\begin{tabular}{lc}
\hline & {$\left[{ }^{14} \mathrm{C}\right]$ Oleate $\rightarrow$ Cholesteryl $\left[{ }^{14} \mathrm{C}\right]$ oleate } \\
\hline & $n m o l / m g$ cell protein per $36 \mathrm{~h}$ \\
LPDS & $0.5 \pm 0.1$ \\
Plasma LDL (human) & $1.1 \pm 0.1$ \\
Lesion LDL (human) & $3.1 \pm 0.9$ \\
Acetyl LDL (human) & $3.7 \pm 1.1$ \\
\hline
\end{tabular}

Human monocytes were isolated and cultured in Iscove's medium for 6-8 d as described in Methods. Before the experiments, cells were preincubated for $24 \mathrm{~h}$ in Iscove's medium containing $5 \mathrm{mg} / \mathrm{ml}$ LPDS. Cells were then washed with PBS and incubated in Iscove's medium containing $25 \mu \mathrm{g} / \mathrm{ml}$ indicated lipoproteins, $0.2 \mathrm{mM}$ $\left[{ }^{14} \mathrm{C}\right]$ oleate-albumin, and $5 \mathrm{mg} / \mathrm{ml}$ LPDS. After $36 \mathrm{~h}$ incubation, cells were washed with PBS and the content of cellular cholesteryl $\left[{ }^{14} \mathrm{C}\right]$ oleate was determined. Human plasma and lesion LDL were from a 41-yr-old male. Each value represents the mean of duplicate determinations $( \pm \mathrm{SD})$
Table IV. Cholesterol Esterification in Mouse Peritoneal Macrophages Incubated with WHHL Rabbit Plasma LDL and Lesion LDL

\begin{tabular}{lc}
\hline & {$\left[{ }^{14} \mathrm{C}\right]$ Oleate $\rightarrow$ Cholesteryl $\left[{ }^{14} \mathrm{C}\right]$ oleate } \\
\hline & $n m o l / m g$ cell protein per $12 \mathrm{~h}$ \\
LPDS & $5.6 \pm 0.6$ \\
Plasma LDL (WHHL) & $3.9 \pm 0.5$ \\
Lesion LDL (WHHL) & $23.3 \pm 3.4$ \\
Acetyl LDL (human) & $27.2 \pm 4.0$ \\
Copper-oxidized $(18 h)$ LDL & \\
$\quad$ (human) & $14.6 \pm 2.7$ \\
\hline
\end{tabular}

Cells were preincubated for $24 \mathrm{~h}$ in DME containing $3.3 \mathrm{mg} / \mathrm{ml}$ LPDS. Cells were then washed with PBS and incubated in DME containing $25 \mu \mathrm{g} / \mathrm{ml}$ indicated lipoproteins, $0.2 \mathrm{mM}\left[{ }^{14} \mathrm{C}\right]$ oleate-albu$\mathrm{min}$, and $3.3 \mathrm{mg} / \mathrm{ml}$ LPDS. After $12 \mathrm{~h}$ incubation, cells were washed with PBS and the content of cellular cholesteryl $\left[{ }^{14} \mathrm{C}\right]$ oleate was determined. Each value represents the mean of duplicate determinations $( \pm \mathrm{SD})$. WHHL rabbit samples were pooled from five animals.

analysis showed that in lesion LDL, but not in LDL isolated from normal human intima, both the intact apo B-100 band and several of the apo $B$ fragments generated during oxidative modification reacted strongly with these antisera (Fig. 4).

Although the analyses were done on a fraction of lipoprotein isolated at or near plasma LDL density, and even though the material was refloated three times, it might be argued that other intimal proteins remained adherent to the LDL. We have preliminary data indicating that traces of immunologically detectable immunoglobulins (Fig. 6), proteoglycans and fibronectin remain associated with LDL isolated from lesions (Ylä-Herttuala, S., J. L. Witztum, and D. Steinberg, unpublished observations). The possibility that these, rather than the apo B of LDL, might contain the epitopes reactive with the antisera is made much less likely, however, by the fact that the fragments react both with antibodies specific for apo B and with antibodies specific for the MDA and 4-HNE epitopes (Figs. 4-6).

Table V. Degradation in Mouse Peritoneal Macrophages of ${ }^{125}$ I-labeled WHHL Rabbit Plasma LDL and Lesion LDL

\begin{tabular}{lc}
\hline & Lipoprotein degraded \\
\hline & $\mu g / m g$ cell protein per $6 h$ \\
Plasma LDL (human) & $1.5 \pm 0.1$ \\
Plasma LDL (WHHL) & $2.6 \pm 0.3$ \\
Lesion LDL (WHHL) & $21.9 \pm 0.7$ \\
Acetyl LDL (human) & $33.2 \pm 1.1$ \\
Copper-oxidized (18 h) LDL (human) & $13.9 \pm 1.2$ \\
\hline
\end{tabular}

Cells were preincubated for $24 \mathrm{~h}$ in DME containing $3.3 \mathrm{mg} / \mathrm{ml}$ LPDS. Cells were then washed with PBS and incubated for $6 \mathrm{~h}$ in DME containing $5 \mu \mathrm{g} / \mathrm{ml}{ }^{125} \mathrm{I}$-labeled lipoproteins and $3.3 \mathrm{mg} / \mathrm{ml}$ LPDS. After the incubation, media were removed and analyzed for TCA-soluble ${ }^{125}$ I radioactivity. Each value represents the mean of triplicate determinations $( \pm \mathrm{SD})$. WHHL rabbit samples were pooled from eight animals. Human LDL was a pooled sample from healthy plasma donors. 


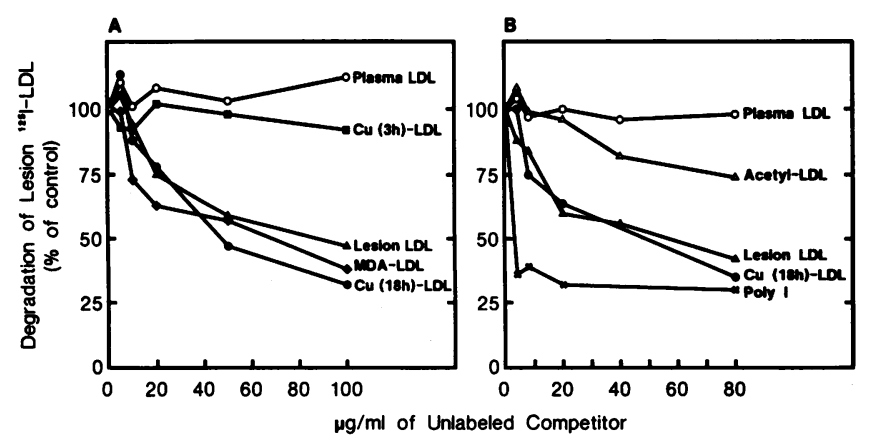

Figure 7. Competition for the degradation of ${ }^{125}$ I-labeled WHHL rabbit lesion LDL in mouse peritoneal macrophages by various unlabeled competitors. Cells were preincubated for $24 \mathrm{~h}$ in DME containing $3.3 \mathrm{mg} / \mathrm{ml}$ LPDS. Cells were then washed with PBS and incubated for $6 \mathrm{~h}$ in DME containing $5(A)$ or $2 \mu \mathrm{g} / \mathrm{ml}(B)$ of lesion ${ }^{125} \mathrm{I}$ $\mathrm{LDL}, 3.3 \mathrm{mg} / \mathrm{ml} \mathrm{LPDS}$ and the indicated concentrations of unlabeled competitors. After the incubation, the media were removed and analyzed for TCA-soluble ${ }^{125}$ I radioactivity. Each point represents the mean of duplicate determinations. The degradation of lesion ${ }^{125} \mathrm{I}-\mathrm{LDL}$ in the absence of competitors was $18.1(A)$ and 10.8 $\mu \mathrm{g} / \mathrm{mg}(B)$ cell protein $/ 6 \mathrm{~h}$, respectively. WHHL rabbit samples were pooled from eight $(A)$ and five $(B)$ animals. $O$, WHHL rabbit plasma LDL; a, human plasma LDL oxidized with copper for $3 \mathbf{h}$; •, human plasma LDL oxidized with copper for $18 \mathrm{~h} ; \Delta$, WHHL rabbit lesion LDL; •, MDA-modified human plasma LDL; $\Delta$, acetylated human plasma LDL; $\times$, poly I. Measurement of TBARS in plasma LDL, lesion LDL, MDA-LDL, and the 3- and 18-h copper-oxidized LDL used in $A$ gave values of $8,11,83,20$, and $61 \mathrm{nmol} / \mathrm{mg}$ protein, respectively.

A third and most compelling line of evidence is the demonstration that lesion LDL shares many biological properties of oxidized LDL. Like oxidized LDL, intimal LDL showed chemotactic activity for human monocytes, whereas LDL isolated from normal human intima was not chemotactic. We previously reported that oxidatively modified $L D L$ is chemotactic for monocytes (and not for neutrophils) (48) partly by virtue of its content of lysophosphatidylcholine (49). However, in view of the large number of chemotactic factors that might be present and that might bind to the LDL, we cannot rule out some other factor as being responsible for the observed activity.

Additional biological evidence that lesion LDL resembles oxidatively modified LDL comes from the competition studies of the degradation of lesion LDL in MPM. We showed that the degradation of ${ }^{125}$ I-labeled WHHL rabbit lesion LDL was competed for by unlabeled lesion LDL, MDA-LDL, LDL oxidized with copper for $18 \mathrm{~h}$, and poly I. Acetyl LDL and LDL oxidized with copper for only $3 \mathrm{~h}$ were less effective, whereas plasma LDL did not compete for the degradation of lesion LDL. Only a few studies have previously tested the ability of various modified LDL preparations to compete for the degradation of ${ }^{125}$ I-labeled lesion LDL. Morton et al. (23) found that the degradation of lesion LDL isolated from postmortem aorta was not competed for by acetyl LDL or unlabeled lesion LDL, whereas Shaikh et al. (25) reported that the degradation of lesion LDL was competed effectively by acetyl LDL. The reason for the contradictory results between these studies remains to be identified, but it may arise from differences in the tissue samples, isolation procedures and/or the cell lines used. Consistent with earlier reports, arterial LDL in the present studies stimulated oleate incorporation into MPM (20, 22-26) and human monocyte-macrophages (25) by several fold compared with normal plasma LDL.

It is noteworthy that in our competition assays, acetyl LDL was a much less effective ligand than LDL oxidized with copper for $18 \mathrm{~h}$. Recent studies by Sparrow et al. (50) and Arai et al. (51) suggest that macrophages express a second class of receptors that bind oxidized LDL in addition to the acetyl LDL receptor. Degradation of oxidized LDL was only incompletely competed for by acetyl LDL $(50,51)$. In the present study, lesion LDL degradation could not be completely competed (i.e., $>90 \%$ ) by any of the tested ligands, suggesting that more than one process was responsible for the uptake and degradation. The presence of small amounts of IgG in the lesion LDL might suggest that macrophage $F_{c}$ receptor-mediated mechanisms may also be involved in the metabolism of lesion LDL. We have recently shown that autoantibodies for MDA-LDL exist in human and rabbit plasma (18).

These studies do not permit us to specify either the proportion of the particles in total lesion LDL or the extent of lysine residues per lesion LDL particle that have been modified. It seems unlikely, however, that all of the particles in lesion LDL are modified in a similar way or to the same extent, since some of the particles may have just entered intima, whereas others may have been retained in the lesion for a prolonged time. Also, the modified lipoproteins presumably would be taken up rapidly by macrophages and thus leave a smaller proportion of heavily modified particles in the steadystate arterial wall pool of LDL. Nevertheless, these results show that, compared with the corresponding plasma LDL, LDL isolated from human and WHHL rabbit atherosclerotic lesions contains particles that have many physical, immunologic, and biologic properties resembling those characteristic of LDL oxidized in vitro $(10-12,14,42,52)$. These data strongly support the conclusion that at least a portion of the LDL found in atherosclerotic lesions has undergone oxidative modification. That conclusion is further supported by the previously reported occurrence, both in rabbits and in man, of autoantibodies that bind to MDA-LDL and 4-HNE-LDL (18). Finally, that antioxidant therapy inhibits lesion formation in the WHHL rabbit $(15,16)$ strongly attests to the importance of oxidized LDL to the atherogenic process.

\section{Acknowledgments}

We thank Dr. Hermann Esterbauer for his generous gift of 4-hydroxynonenal, Dr. Linda Curtiss for assistance with the immunological studies, and Dr. John Khoo and Elizabeth Miller for help in obtaining human monocyte-macrophages. Further, we wish to thank Mickey Masteller and the Tissue Transplantation Center at University of California, San Diego, Joellen Barnett, Nonna Kondratenko, Paula Sicurello, and Rosanne Odom for technical assistance.

This work was supported by National Heart, Lung, and Blood Institute (NHLBI) grant HL-14197. Support for S. Ylä-Herttuala came from a Fogarty International Fellowship Award U. S. Public Health Service grant F5TWO4095A and a grant from the Emil Aaltonen Foundation (Finland); W. Palinski was a Research Fellow of the Deutsche Forschungsgemeinschaft.

\section{References}

1. Smith, E. B. 1974. The relationship between plasma and tissue lipids in human atherosclerosis. Adv. Lipid Res. 12:1-49.

2. Steinberg, D. 1988. Metabolism of lipoproteins and their role in the pathogenesis of atherosclerosis. Atherosclerosis Rev. 18:1-23.

3. Fowler, S., H. Shio, and N. J. Haley. 1979. Characterization of lipid-laden aortic cells from cholesterol-fed rabbits. IV. Investigation of 
macrophage-like properties of aortic cell populations. Lab. Invest. 41:372-378.

4. Schaffner, T., K. Taylor, E. J. Bartucci, K. Fischer-Dzoga, J. H. Beeson, S. Glagov, and R. W. Wissler. 1980. Arterial foam cells with distinctive immunomorphologic and histochemical features of macrophages. Am. J. Pathol. 100:57-80.

5. Gerrity, R. G. 1981. The role of the monocyte in atherogenesis. I. Transition of blood-borne monocytes into foam cells in fatty lesions. Am. J. Pathol. 103:181-190.

6. Faggiotto, A., R. Ross, and L. Harker. 1984. Studies of hypercholesterolemia in the nonhuman primate. I. Changes that lead to fatty streak formation. Arteriosclerosis. 4:323-340.

7. Goldstein, J. L., Y. K. Ho, S. K. Basu, and M. S. Brown. 1979. Binding site on macrophages that mediates uptake and degradation of acetylated low density lipoprotein, producing massive cholesterol deposition. Proc. Natl. Acad. Sci. USA. 76:333-337.

8. Mahley, R. W., T. L. Innerarity, K. H. Weisgraber, and S. Y. Oh. 1979. Altered metabolism (in vivo and in vitro) of plasma lipoproteins after selective chemical modification of lysine residues of the apoproteins. J. Clin. Invest. 64:743-750.

9. Fogelman, A. M., I. Shechter, J. Seager, M. Hokom, J. S. Child, and P. A. Edwards. 1980. Malondialdehyde alteration of low density lipoproteins leads to cholesteryl ester accumulation in human monocyte-macrophages. Proc. Natl. Acad. Sci. USA. 77:2214-2218.

10. Henriksen, T., E. M. Mahoney, and D. Steinberg. 1981. Enhanced macrophage degradation of low density lipoprotein previously incubated with cultured endothelial cells: recognition by receptors for acetylated low density lipoproteins. Proc. Natl. Acad. Sci. USA. 78:6499-6503

11. Henriksen, T., E. M. Mahoney, and D. Steinberg. 1982. Interactions of plasma lipoproteins with endothelial cells. Ann. NY Acad. Sci. 401:102-116.

12. Steinbrecher, U. P., S. Parthasarathy, D. S. Leake, J. L. Witztum, and D. Steinberg. 1984. Modification of low density lipoprotein by endothelial cells involves lipid peroxidation and degradation of low density lipoprotein phospholipids. Proc. Natl. Acad. Sci. USA. 81:3883-3887.

13. Heinecke, J. W., L. Baker, H. Rosen, and A. Chait. 1986. Superoxide-mediated modification of low density lipoprotein by arterial smooth muscle cells. J. Clin. Invest. 77:757-761.

14. Parthasarathy, S., D. J. Printz, D. Boyd, L. Joy, and D. Steinberg. 1986. Macrophage oxidation of low density lipoprotein generates a modified form recognized by the scavenger receptor. Arteriosclerosis. 6:505-510.

15. Carew, T. E., D. C. Schwenke, and D. Steinberg. 1987. An antiatherogenic effect of probucol unrelated to its hypocholesterolemic effect: evidence that antioxidants in vivo can selectively inhibit low density lipoprotein degradation in macrophage-rich fatty streaks slowing the progression of atherosclerosis in the WHHL rabbit. Proc. Natl. Acad. Sci. USA. 84:7725-7729.

16. Kita, T., Y. Nagano, M. Yokode, K. Ishii, N. Kume, A. Ooshima, H. Yoshida, and C. Kawai. 1987. Probucol prevents the progression of atherosclerosis in Watanabe heritable hyperlipidemic rabbit, an animal model for familial hypercholesterolemia. Proc. Natl. Acad. Sci. USA. 84:5928-5931.

17. Haberland, M. E., D. Fong, and L. Cheng. 1988. Malondialdehyde-altered protein occurs in atheroma of Watanabe heritable hyperlipidemic rabbits. Science (Wash. DC). 241:215-218.

18. Palinski, W., M. E. Rosenfeld, S. Ylä-Herttuala, G. C. Gurtner, S. S. Socher, S. W. Butler, S. Parthasarathy, T. E. Carew, D. Steinberg, and J. L. Witztum. 1989. Low density lipoprotein undergoes oxidative modification in vivo. Proc. Natl. Acad. Sci. USA. 86:1372-1376.

19. Hollander, W., J. Paddock, and M. Colombo. 1979. Lipoproteins in human atherosclerotic vessels. Exp. Mol. Pathol. 30:144-171.

20. Goldstein, J. L., H. F. Hoff, Y. K. Ho, S. K. Basu, and M. S. Brown. 1981. Stimulation of cholesteryl ester synthesis in macrophages by extracts of atherosclerotic human aortas and complexes of albumin/cholesterol. Arteriosclerosis. 1:210-226.
21. Hoff, H. F., and J. W. Gaubatz. 1982. Isolation, purification and characterization of a lipoprotein containing apo B from the human aorta. Atherosclerosis. 42:273-297.

22. Clevidence, B. A., R. E. Morton, G. West, D. M. Dusek, and J. F. Hoff. 1983. Cholesterol esterification in macrophages. Stimulation by lipoproteins containing apo B isolated from human aortas. Arteriosclerosis. 4:196-207.

23. Morton, R. E., G. A. West, and H. F. Hoff. 1986. A low density lipoprotein-sized particle isolated from human atherosclerotic lesions is internalized by macrophages via a non scavenger-receptor mechanism. J. Lipid Res. 27:1124-1134.

24. Ylä-Herttuala, S., O. Jaakkola, C. Ehnholm, M. J. Tikkanen, T. Solakivi, T. Särkioja, and T. Nikkari. 1988. Characterization of two lipoproteins containing apolipoproteins B and E from lesion-free human aortic intima. J. Lipid Res. 29:563-572.

25. Shaikh, M., S. Martini, J. R. Quiney, P. Baskerville, A. E. LaVille, N. L. Browse, R. Duffield, P. R. Turner, and B. Lewis. 1988. Modified plasma-derived lipoproteins in human atherosclerotic plaques. Atherosclerosis. 69:165-172.

26. Daugherty, A., B. S. Zweifel, B. E. Sobel, and G. Schonfeld. 1988. Isolation of low density lipoprotein from atherosclerotic vascular tissue of Watanabe heritable hyperlipidemic rabbits. Arteriosclerosis 8:768-777.

27. Jürgens, G., J. Lang, and H. Esterbauer. 1986. Modification of human low-density lipoprotein by the lipid peroxidation product 4hydroxynonenal. Biochim. Biophys. Acta. 875:103-114.

28. Esterbauer, H., G. Jürgens, O. Quehenberger, and E. Koller. 1987. Autoxidation of human low density lipoprotein: loss of polyunsaturated fatty acids and vitamin $\mathrm{E}$ and generation of aldehydes. $J$. Lipid Res. 28:495-509.

29. Steinbrecher, U. P., J. L. Witztum, S. Parthasarathy, and D. Steinberg. 1987. Decrease in reactive amino groups during oxidation or endothelial cell modification of LDL. Correlation with changes in receptor-mediated catabolism. Arteriosclerosis. 7:135-143.

30. Steinbrecher, U. P. 1987. Oxidation of human low density lipoprotein results in derivatization of lysine residues of apolipoprotein B by lipid peroxide decomposition products. J. Biol. Chem. 262:3603-3608.

31. Schuh, J., G. F. Fairclough, Jr., and R. H. Haschemeyer. 1978. Oxygen-mediated heterogeneity of apo-low-density lipoprotein. Proc. Natl. Acad. Sci. USA. 75:3173-3177.

32. Lee, D. M., A. J. Valente, W. H. Kuo, and H. Maeda. 1981. Properties of apolipoprotein $B$ in urea and in aqueous buffers. The use of glutathione and nitrogen in its solubilization. Biochim. Biophys. Acta. 666:133-146.

33. Khoo, J. C., E. Miller, P. McLoughlin, and D. Steinberg. 1988. Enhanced macrophage uptake of low density lipoprotein after self-aggregation. Arteriosclerosis. 8:348-358.

34. Havel, R. J., H. A. Eder, and J. H. Bragdon. 1955. The distribution and chemical composition of ultracentrifugally separated lipoproteins in human serum. J. Clin. Invest. 34:1345-1353.

35. Lowry, O. H., N. J. Rosebrough, A. L. Farr, and R. J. Randall. 1951. Protein measurement with the Folin phenol reagent. J. Biol. Chem. 193:265-275.

36. Jung, D. H., H. G. Biggs, and W. R. Moorehead. 1975. Colorimetry of serum cholesterol with use of ferric acetate/uranyl acetate and ferrous sulfate/sulfuric acid reagents. Clin. Chem. 21:1526-1530.

37. Young, S. G., R. S. Smith, D. M. Hogle, L. K. Curtiss, and J. L. Witztum. 1986. Two new monoclonal antibody-based enzyme-linked assays of apolipoprotein B. Clin. Chem. 32:1484-1490.

38. Young, S. G., S. J. Bertics, T. M. Scott, B. W. Dubois, L. K. Curtiss, and J. L. Witztum. 1986. Parallel expression of the MB19 genetic polymorphism in apoprotein B-100 and apoprotein B-48. $J$. Biol. Chem. 261:2995-2998.

39. Young, S. G., J. L. Witztum, D. C. Casal, L. K. Curtiss, and S. Bernstein. 1986. Conservation of the low density lipoprotein receptorbinding domain of apoprotein B: demonstration by a new monoclonal antibody, MB47. Arteriosclerosis. 6:178-188.

40. Curtiss, L. K., and T. S. Edgington. 1982. Immunochemical 
heterogeneity of human plasma apolipoprotein B: apolipoprotein B binding of mouse hybridoma antibodies. J. Biol. Chem. 257:1521315221.

41. Curtiss, L. K., and J. L. Witztum. 1983. A novel method for generating region-specific monoclonal antibodies to modified proteins: application to the identification of human glucosylated low density lipoproteins. J. Clin. Invest. 72:1427-1438.

42. Fong, L. G., S. Parthasarathy, J. L. Witztum, and D. Steinberg 1987. Nonenzymatic oxidative cleavage of peptide bonds in apoprotein $\mathrm{B}_{100}$. J. Lipid Res. 28:1466-1477.

43. Basu, S. K., J. L. Goldstein, R. G. W. Anderson, and M. S. Brown. 1976. Degradation of cationized low density lipoprotein and regulation of cholesterol metabolism in homozygous familial hypercholesterolemia fibroblasts. Proc. Natl. Acad. Sci. USA. 73:3178-3182.

44. Salacinski, P. R. P., C. McLean, J. E. C. Sykes, V. V. ClementJones, and P. J. Lowry. 1981. Iodination of proteins, glycoproteins, and peptides using a solid-phase oxidizing agent, 1,3,4,6-tetrachloro$3 \alpha, 6 \alpha$-diphenyl glycoluril (Iodogen). Anal. Biochem. 117:136-146.

45. Sepracell-MN Separation Manual. 1988. Sepratech Corporation Publ. No. 1187CJH.

46. Weinstein, D. B., T. E. Carew, and D. Steinberg. 1976. Uptake and degradation of low density lipoprotein by swine arterial smooth muscle cells with inhibition of cholesterol biosynthesis. Biochim. Biophys. Acta. 424:404-421.
47. Goldstein, J. L., S. K. Basu, and M. S. Brown. 1983. Receptormediated endocytosis of low-density lipoprotein in cultured cells. Methods Enzymol. 98:241-260.

48. Quinn, M. T., S. Parthasarathy, L. G. Fong, and D. Steinberg. 1987. Oxidatively modified low density lipoproteins: a potential role in recruitment and retention of monocyte/macrophages during atherogenesis. Proc. Natl. Acad. Sci. USA. 84:92995-2998.

49. Quinn, M. T., S. Parthasarathy, and D. Steinberg. 1988. Lysophosphatidylcholine: a chemotactic factor for human monocytes and its potential role in atherogenesis. Proc. Natl. Acad. Sci. USA. 85:2805-2809.

50. Sparrow, C. P., S. Parthasarathy, and D. Steinberg. 1989. A macrophage receptor that recognizes oxidized LDL but not acetylated LDL. J. Biol. Chem. 264:2599-2604.

51. Arai, H., T. Kita, M. Yokode, S. Narumiya, and C. Kawai. 1989. Multiple receptors for modified low density lipoproteins in mouse peritoneal macrophages: different uptake mechanisms for acetylated and oxidized low density lipoproteins. Biochem. Biophys. Res. Commun. 159:1375-1382.

52. Parthasarathy, S., U. P. Steinbrecher, J. Barnett, J. L. Witztum, and D. Steinberg. 1985. Essential role of phospholipase $A_{2}$ activity in endothelial cell-induced modification of low density lipoprotein. Proc. Natl. Acad. Sci. USA. 82:3000-3004. 